\title{
Building research capacity in Education: evidence from recent initiatives in England, Scotland and Wales.
}

Zoe Fowler, Adela Baird, Stephen Baron, Susan M.B.Davies, Richard Procter and Jane Salisbury.

Corresponding author: Zoe Fowler, Independent Education Consultant

Email: zfowler.ed@gmail.com

Keywords: research capacity building; research workforce; professional

development; collaboration; research careers, expertise.

\begin{abstract}
Challenges facing researcher development are explored in relation to three UK case study initiatives of building research capacity in Education. Drawing evidence from evaluations of these initiatives, we argue that expansive research workplaces build research capacity particularly effectively. The nature of expansiveness is dependent upon the range of learning opportunities, engagement with research communities and interpersonal support. The importance of inter-institutional collaboration to promote capacity across the academic discipline is also highlighted. We conclude that the development of, engagement with, and investment in inter-institutional, interproject communities is imperative to the effective building of research capacity.
\end{abstract}

\section{Introduction}

This paper provides a description of three initiatives which have sought to build research capacity through enhancing the professional development of research staff in Education within the United Kingdom. Capacity building is not only about recruiting sufficient research staff to the field: it is about enabling those people to progress so that they are able to sustain and develop their academic field, both in the here-andnow and in the future. It is also about building inter-institutional collaborations so that academic research is able to thrive. The first part of this paper identifies external factors which frame academic research in the UK, and explores the impact that these have upon the research workforce in Education and more widely. Three recent initiatives within Education which have sought to build research capacity are then described. Evidence from evaluations of these initiatives informs the central argument of this paper: that research capacity is built most effectively through expansive working environments in which interpersonal and institutional support is given to the professional development of research staff at all stages of their careers.

Many academic disciplines and fields face capacity building challenges in the contemporary world. It is hoped that this paper may inform more nuanced and 
sophisticated understandings of the factors which contribute to meaningful researcher development and to effective scientific capacity building.

\section{Providing the context: external factors and educational research in the UK}

Education is the second largest of the social science disciplines in the UK. Through the Teaching and Learning Research Programme (TLRP), Education became the first of the social sciences to explicitly identify research capacity building as a priority objective of an ESRC-funded programme. Many of the factors which impact upon Education, as an academic discipline, are generic to the social sciences and have implications for academic research in general. This first part of the paper scans these external factors, clarifies their possible impact, and provides the context within which the three capacity building initiatives operated.

As with other disciplines, Education is faced with often competing demands to develop research quality and to build research capacity across the UK system. These demands relate to Higher Education (HE) policy and the increasing concentration of research resources in a limited number of institutions, the economic structuring of Higher Education Institutions (HEls), the demographics of the research workforce, the engagement of potential users of educational research, and the need to build future sustainability across the field.

The predominance of visible performance measures for quality research outputs, most prominently through the Research Assessment Exercise, and the allocation of quality-related research (QR) funding according to RAE outcomes led to an increasing concentration of Education funding and research in a small number of research intensive institutions (Munn, 2008) thereby contributing to a polarisation between research-intensive universities and the remainder of the field (Pollard, 2006). This context does not encourage collaboration between institutions. The problem exists across UK institutions, but is, perhaps, most pronounced in Wales (Rees and Power, 2007) where an acute differentiation has occurred between Cardiff, a $5^{*}$ institution, and other universities that receive no core education research funding. Across the UK, this differentiation has resulted in expertise becoming fragmented and isolated, causing researchers to lack important opportunities to develop expertise by working alongside more knowledgeable peers located in different institutions. The prioritisation given to research by the host institution also has an impact upon researchers' working practices. The potential for individuals to engage with capacity building activity, especially in institutions where research has a low priority, is likely to be influenced by the willingness of an institution to facilitate a more flexible approach to the use of staff time for research.

Within Education in particular, many institutions which have low research capacity have high levels of connectedness with educational policy and practice through the delivery of initial teacher education (ITE), continuing teacher professional 
development (CPD), and mentoring of practitioner research; however the applied and pedagogical research that might be most relevant to these universities often struggles to achieve funding, leading to the very real possibility that education training becomes divorced from its research base. This raises issues for how research in Education might work most effectively with potential users of the research. As Munn (2008: 413) indicates, "capacity refers not only to educational researchers themselves but to the users and commissioners of research to understand what diverse forms of educational research have to offer".

Political and economic factors have contributed significantly to the increased focus on building research capacity in the academy. Changes in funding have led HE to become increasingly subjected to wider labour market pressures, with the consequences that institutions have needed to focus upon increasing efficiency, reducing overheads, and competing for funding against other institutions (Reay, 2000; Davies and Holloway, 1995). These factors have contributed, in particular, to the significant increase in the numbers of research staff employed on fixed term contracts, often attached to specific research projects. Fixed term contracts can be an inefficient means of growing research capacity: insecurity of tenure can generate anxiety and distract researchers from their current projects, restrict opportunities for professional development, and act against the individual's development of a coherent body of expertise as they move between unrelated research projects (Fowler and Procter, 2008). Typically, short-term funded research projects have little opportunity to invest in building research capacity. These factors affect professional identifies, and the ways in which knowledge grows and research communities are formed in specific fields (Oancea, 2009).

While more recent trends have been away from fixed-term employment contracts and towards open-ended contracts, partly as a result of EU fixed-term employment legislation that came into effect in 2006, this shift might represent an attempt at minimal legal compliance rather than any broader cultural change to raise the status and profile of research staff (Mills, 2009).

Most social science disciplines are experiencing the demographic challenges of an ageing workforce. In Education, these challenges are particularly pressing: $70 \%$ of staff are aged over 45 (Mills et al., 2006) and a sizeable proportion of senior academics are looking forwards towards their retirement over the coming few years. Evidence suggests that there are insufficient younger researchers with the capacity to replace these senior academics (Mills et al., 2006) and there is an urgent need to ensure that research is shared effectively so that it is not lost when senior people retire:

The body of senior research staff that predated the change in teacher training policy are shortly coming up for retirement. They have a significant body of knowledge and expertise, which cannot be passed on through the traditional 
apprenticeship model of academia because much current research in the field is piecemeal and practice-based. (Mills et al. 2006: 44)

The impending labour shortfall in Education is particularly pronounced due to the characteristics of this workforce. The majority of research staff are recruited to the field following earlier careers in policy or practice. This variety of career background and previous professional experience is a strength of a field which focuses upon applied research, but contributes to the difficulties in attempting to define the typical 'researcher' (Freedman et al., 2000: 42). Without an agreed model of a typical researcher, it is difficult to define typical professional development needs. While it is recognised that expertise needs to be shared and developed between established and beginning researchers (Dyson and Desforges, 2002; Mclntyre and McIntyre, 1999), the complex nature and huge scale of the field mean that this process is, inevitably, problematic.

As with other fields in the social sciences, there are widespread concerns that too few researchers will have the ability to lead the design, delivery, and dissemination of quality research in the near future. Capacity building strategies need to address how mid-career researchers can develop the skills necessary to manage and direct research projects, as well as ensuring professional development opportunities for beginning researchers. Capacity building approaches also need to be responsive to the needs of the overall field as well as the professional development needs of individual researchers: capacity building needs to be pitched at several levels, including organisational, sectoral and national levels. Munn (2008) argues that the research capacity of policy makers and practitioners also need to be developed within this wider strategic approach.

How can expertise be shared most effectively across the research workforce? Rees et al (2007: 776) have recommended that an exploration is needed of "the everyday practices characteristic of the work of researchers and the wider social organisation of educational research within which these are located". This paper draws on evidence from evaluations of three recent capacity building initiatives across the UK to explore how researchers' experiences of research work, engagement in research projects, and participation in wider research networks have contributed to their professional development, or otherwise. A brief overview of the initiatives and the methodological structure of their evaluations is given in the following section.

Evidence from these evaluations will then inform the central argument of this paper. 


\section{Recent capacity building initiatives in England, Scotland and Wales}

\section{$\underline{\text { The Teaching and Learning Research Programme }}$}

Set up in 1998 and funded by the Economic and Social Research Council (ESRC), the Teaching and Learning Research Programme (TLRP) supported and developed educational research across the UK for a decade. One of TLRP's core aims was to work to enhance capacity for all forms of research on teaching and learning and the Programme was the first of the ESRC's investments to explicitly identify research capacity building as one of its principle purposes. The programme wide capacity building structures included:

- regular conferences;

- a Research Capacity Building Network (RCBN), which provided formal training courses and a journal aimed specifically at early career researchers;

- a website providing access to a substantial bank of on-line resources and links towards other capacity building resources;

- Meeting of Minds Fellowships, which funded mentoring relationships between early career researchers and the next generation of research leaders.

Additionally, each research project was also required to develop research capacity. While the majority of research projects focused upon project-led and programme-led activities, some projects also provided evidence of capacity building through engaging with policy and practice, and contributing to the host institution through providing workshops and dissemination activities. These activities were recorded in the annual and end-of-project reports: the range of responses included in this section of the form evidences the lack of clarity of what might be meant by capacity building (Rickinson et al., 2005), but also focuses attention on the diversity of ways in which capacity might be grown. Related research capacity building projects across the UK, including the TERN project, the Teacher Education Group, WERN, AERS, and the Social and Professional Network for Early Career Researchers in Education project, have all been actively supported by the TLRP.

The evaluation of TLRP's capacity building structures and activities (the Mapping the Ripples project ${ }^{1}$ ) drew evidence from existing TLRP databases and archived project reports. On-line surveys were distributed to educational researchers (working on TLRP and non-TLRP projects) to investigate their ways of working and communicating, and to TLRP Awardholders to investigate good practice within the field. Responses to the surveys are summarised in table 1.

\footnotetext{
${ }^{1}$ This evaluation project was undertaken between July 2007 and May 2008 by Zoe Fowler and Richard Procter, with support from Madeleine Stevens at the Social Science Research Unit, Institute of Education. For more information on this project, see http://www.tlrp.org/mappingtheripples/
} 


\begin{tabular}{|l|l|l|}
\hline \multicolumn{1}{|c|}{ Sample population } & Distribution rate of survey & \multicolumn{1}{|c|}{ Response rate } \\
\hline TLRP researchers & $\begin{array}{l}\text { 232 researchers (derived } \\
\text { from analysis of existing } \\
\text { TLRP databases) }\end{array}$ & $\begin{array}{l}\mathrm{n}=92 \text { (40\% response } \\
\text { rate) }\end{array}$ \\
\hline Non-TLRP researchers & $\begin{array}{l}\text { Opportunistic sampling at } \\
\text { research conferences and } \\
\text { through Education } \\
\text { departments across the } \\
\text { UK }\end{array}$ & $\mathrm{n}=50$ \\
\hline TLRP project directors & $\begin{array}{l}303 \text { Project Directors } \\
\text { (derived from existing } \\
\text { TLRP databases) }\end{array}$ & $\begin{array}{l}\mathrm{n}=68(21 \% \text { response } \\
\text { rate) }\end{array}$ \\
\hline
\end{tabular}

Table 1: Summary of distribution and response rate of MTR surveys.

The TLRP researcher and Awardholder surveys generated both quantitative and qualitative data: quantitative data were analysed statistically to describe demographic and experiential aspects of this population and to show trends in opinions across respondents; open-ended sections were systematically grouped to provide evidence of similarities and differences across cases, and descriptive quotes from these sections were used to illustrate findings from the statistical analysis. The analysis of the survey data informed the interview schedules and twelve interviews were then conducted with research staff who represented a range of institutions, staff backgrounds, and research projects. Interview data were analysed through a coding frame informed by the literature review, concepts developed from workplace learning literature, and emerging themes.

Together these data lead to a greater understanding of how involvement with the TLRP has shaped and influenced career trajectories and intellectual journeys within the educational research field.

\section{The Applied Educational Research Scheme}

The Applied Educational Research Scheme (AERS) was funded for five years from 2004 by the Scottish Funding council and the Scottish government, with the aims of building research capacity collaboratively across the seven universities in Scotland which provide initial teacher education, and of conducting quality research in support of the National Priorities in Education (TSG, 2003). AERS was a much smaller scheme than TLRP with a budget of $£ 2$ million, although the scheme worked closely with the larger TLRP. To provide a research focus for the planned capacity building, AERS was organised into three substantive networks and each Network supported a 
range of research projects. This organisational structure was different to that of the TLRP in that the Networks determined the scope and focus of the projects. Thus the three AERS networks provided the main locus of 'on the job' training, where provision emerged out of the needs of the project rather than the individual's preferred or chosen needs. AERS also supported a Research Capacity Building Network (RCBN) which had a generic responsibility for capacity building, both by developing a formal Masters training programme and by responding to the ongoing needs for training across the substantive networks, thereby providing both 'on' and 'off' the job training.

In order to track the research activity in each of the three substantive Networks ${ }^{2}$, online questionnaires were distributed to three different types of participants.

Questionnaires which identified the range and purpose of the research capacity building activities, identified from which communities the participants had come, and their perceptions of the impact of being involved in a research project, were distributed to two researcher populations: 1) Level 1 participants (defined as being people kept informed about the activities of the Network but not being actively involved in any of the research projects; 2) participants actively involved in one of the research projects (these included Level 2 participants who were active in a project but not one of the core group of researchers, Level 3 participants who had a consistent commitment to a project and AERS Fellows, who were participants with a formal learning contract between AERS, themselves and their home institution). Each of these categories included representatives from the academic, policy and practice communities. The third questionnaire was completed by the Principal Investigators (PIs), the more established researchers charged with forming the research teams so as to deliver 'on the job' capacity building. Opportunities were provided within each of the questionnaires for the participants to offer personal opinions on a range of issues. The main questionnaire (see 2 above) had 40 returns from a potential number of 76 , giving a response rate of just under $54 \%$ ( $76 \%$ for Fellows). Eight Principal Investigators out of a total of 14 potential respondents completed the $\mathrm{PI}$ questionnaire, giving a response rate of just over $57 \%$. Apart from the Level 1 survey, which is not being used for any major analysis, these results are adequate in sampling the views of the 'active research' participants across the scheme.

Follow-up focus-groups were conducted with 11 of the 21 Fellows. These explored in more detail the social practice model(s) of research training within the AERS Networks and projects. Additionally, these focus groups sought to capture how new forms of knowledge have been produced, the ways the participants have been affected by their involvement in a research project, and their plans for the future. These qualitative data supplemented the quantitative data from the web-based

\footnotetext{
${ }^{2}$ This evaluation was led by Adela Baird and Stephen Baron in the Summer of 2008. The AERS website is http://www.aers.org.uk/aers/
} 
questionnaire and helped illustrate how being active in the research process itself could be instrumental in developing new understandings of research findings.

In a similar vein to the TLRP data, the AERS surveys included both qualitative and quantitative data. Using a web-based analysis tool, The Bristol On-Line Survey, the quantitative data were analysed to identify demographic trends and to highlight differences between the AERS research populations and the Networks in which they were involved. The open-ended sections within the questionnaires were scrutinised to identify emerging trends and to substantiate findings from the statistical analysis. The scope of the focus group interviews was informed by the emerging findings from the on-line surveys, and these were transcribed and analysed intuitively by selecting common themes and concerns.

\section{The Welsh Education Research Network}

The Welsh Education Research Network (WERN) was funded by the ESRC and HEFCW for a pilot period between $1^{\text {st }}$ October 2007 and June 2008, this was then extended to July 2009. This paper reports on the initial phase from 2007-08. More pronounced than other areas of the UK, institutions in Wales are differentiated by the presence or absence of a viable and active research infrastructure: researchers frequently lack important opportunities to develop expertise by working alongside more knowledgeable peers. The Network aims to develop research capacity by building a collaborative partnership, which shares expertise between all the higher education institutions (HEls) with education and related departments in Wales. WERN's strategy uses a social practices model of work based learning to build capacity by inter-institutional collaborative research activity, providing opportunities for joint activity and social learning between partners with various levels of expertise and experience. The Network was actively supported and encouraged by Heads of Faculty, heads of schools, and several vice-chancellors.

The principal method of developing capacity in 2007-08 was through the provision of bursaries to support groups of colleagues from different institutions to work together to write a proposal for research funding; thereby bringing together expertise from different institutions centred on a task that requires thinking, discussion and sometimes implementation of essential research skills: reviewing the literature, identifying a research question, making decisions about, and trialling appropriate methodologies etc. There was also the added bonus that the proposal could be successful in attracting further funding if an award was made. An essential criterion for receipt of bursary funding was a mix of skills and experience within the group that had the potential to build the capacity of the group members. Groups were also expected to find a mentor, that is a researcher with high levels of expertise and of high academic standing in their field, who would provide occasional supervision sessions for the group. The involvement of the mentor meant that even for the bursary group leader (generally an experienced researcher) there would be opportunities for learning from a more expert peer. 
Eight funded bursary groups included in total 27 early career researchers ( 5 male and 22 female) with an even spread of experienced and less experienced researchers, and all but two institutions had members of staff participating in these bursary groups, with a total of 51 academics in Wales being involved in bursary activity. By the end of the bursary period, all groups had proposals underway, one had been submitted and this was successful in gaining an award. Significant tangible outcomes were achieved: for example, papers were written and presented at eight major conferences during the academic year 2007-08, four journal articles were submitted and accepted, and five early career researchers further developed their research profile through enrolling for doctorates or other post-graduate research training.

The material discussed here is informed by data drawn from the evaluation of the initial pilot phase, through an internal evaluation ${ }^{3}$ and an external evaluation (Gardner, 2008). Internal evaluation data on the bursary groups were gathered on three occasions. All group leaders provided interim and final reports during the course of their bursaries, and subsequent updates in which they outlined the group's activities and outputs. These were then collated across cases. Individual group members also provided evidence of their experiences and opinions on two occasions after the formal funding period had finished. Firstly, immediately after they were asked to reflect on and record their own impressions of being a bursary member participant; these qualitative responses were systematically grouped to identify the key aspects of experience shared by individuals. To progressively focus upon experiential gains, all bursary members were asked to complete a self-rating survey tool. The questionnaire asked them to rate their skill and confidence levels for ten different types of research activity (ranging from identifying a research question to research management and leadership) before and after their involvement in the bursary group. 32 bursary group members (65\%) sent in responses providing a good cross section of new, second career, mid career, and experienced researchers. All groups showed an increase in perceived skill with most the greatest increase evident for early and second career researchers. These self reports are congruent with the findings of Gardner's (2008) external evaluation: bursary group members perceived the experience as an effective method for developing research skills. To investigate institutional infrastructure changes caused by WERN, interviews were undertaken with representatives from each institution. Interview data were analysed to identify evidence of changes and to describe similarities and differences across the HEI cases.

\footnotetext{
${ }^{3}$ An internal evaluation of the WERN project was carried out in the Summer of 2008 by Susan M. B. Davies and Jane Salisbury. More information on this project is available at http://www. trinity$\mathrm{cm}$. ac.uk/english/research/education/wern/wern.asp
} 
While acknowledging the possible weaknesses associated with the 'self-reporting' evaluations of these initiatives, we demonstrate how this data highlights important areas for future consideration.

Each of these three evaluations share an understanding of research capacity which encompasses the competences of research staff to produce and manage quality research and to grow educational research as an academic field; the building of inter-institutional collaboration so that educational research can thrive within current and future policy and political climates; and the enhancement of opportunities for and engagement with research findings across policy, research and practitioner audiences. The next section of this paper relates the findings of these evaluations to the challenges and issues facing educational research, and academic research more generally, which were identified at the beginning of this paper.

\section{Findings}

\section{Expansive research projects}

In terms of professional development, capacity is built most effectively when provision responds to the diverse needs of the workforce and seeks to build upon the foundations which are already in place. Evidence from the evaluations of these three initiatives would seem to concur that the most effective and positively valued capacity building took place through 'expansive' research projects. We derive our concept of 'expansive research projects' from research analysing how work organisations differ in the ways that they create and manage themselves as learning environments (Fuller et al, 2007; Evans et al, 2006; Fuller and Unwin, 2004). These authors develop the conceptual framework of an expansive-restrictive continuum of workplace factors, and this provides a useful vehicle for bringing together the pedagogical, organisational and cultural factors that contribute to workplace learning and for understanding the interaction between institutional context, workplace learning environment, and individual learning. Features of the research workplace 'influence the extent to which the workplace as a whole creates opportunities for, or barriers to, learning' (Evans et al., 2006: 35)

So, what might an expansive research workplace look like? Figure 1 summarises some of the main features which an expansive research workplace might include (a more extensively worked version of this figure is discussed in Fowler and Procter, 2008). 


\begin{tabular}{|l|l|}
\hline \multicolumn{2}{|c|}{ Expansive } \\
\hline $\begin{array}{l}\text { Access and encouragement to attend off- } \\
\text { the-job training }\end{array}$ & Limited access to off-the-job training \\
\hline $\begin{array}{l}\text { Supported engagement with multiple } \\
\text { communities of practice }\end{array}$ & $\begin{array}{l}\text { Limited exposure to multiple } \\
\text { communities of practice outside of } \\
\text { research team }\end{array}$ \\
\hline $\begin{array}{l}\text { Interpersonal support } \\
\text { Balance between project outputs and } \\
\text { researchers' own professional } \\
\text { development }\end{array}$ & $\begin{array}{l}\text { Lack of interpersonal support } \\
\text { professional development needs of } \\
\text { individuals }\end{array}$ \\
\hline $\begin{array}{l}\text { Ongoing commitment to researchers' } \\
\text { futures beyond the end of the project }\end{array}$ & $\begin{array}{l}\text { Abrupt ending to the project with no } \\
\text { further investment in research staff. }\end{array}$ \\
\hline
\end{tabular}

\section{Figure !: features of the expansive/restrictive workplace}

The researcher's work context needs to expand beyond the community, demands, knowledge, and timeframe of her immediate research project. If her capacity as a researcher is to be developed, she needs to have opportunities to learn and grow beyond the requirements of the job-in-hand.

The dominant models of learning which seem to have informed capacity building strategies are skills-building approaches, which tend to focus upon the provision of formal training, and accounts of situated learning which focus upon the acquisition of tacit forms of knowledge and skill through legitimate peripheral participation in communities of practice which involve beginners in real and authentic work-based activities (Lave and Wenger, 1991; Wenger, 1998). There are, inevitably, strengths and limitations to both models, and the acquisition of expertise is best achieved through a combination of both formal and informal learning (Eraut and Hirsch, 2007). Rees et al. (2007) stress the importance of recognising the different roles that forms of professional learning can play in relation to capacity building. An expansive workplace provides opportunities to generate a balance between situated learning and wider opportunities. The nature of that balance needs to be responsive to the unique needs of the individual, in relation to their professional backgrounds, their current working practices, and their future career aspirations.

The initiatives described in this paper provided different approaches to combining off-the-job and on-the-job learning. In Wales, a wide range of professional development was recorded by participants with a particularly positive endorsement for the social practices approach. Perhaps because of the strong emphasis on the 
collaborative nature of bursary groups, the advantages were seen to outweigh the disadvantages when compared with more formal types of training:

"... the learning advantages of working on a 'real' research bid with experienced colleagues and an inspiring mentor cannot be replicated by a training environment. In the model adopted new learning was used and put into practice immediately rather than, as can be the case with new training, new skills are not practiced and have to await until an opportunity for use presents itself." [WERN Second career researcher]

However, the evaluations of both AERS and TLRP demonstrated the value of formal training coexisting alongside opportunities to learn 'on-the-job'. In Scotland, AERS adopted a model of capacity building which was designed to give a new generation of academic researchers opportunities to learn 'on the job', combined with providing further opportunities for learning 'off the job' through a formal Masters training programme which was delivered through a range of on-line resources. A strength of this formal training programme was its flexibility in terms of access due to the virtual nature of provision (Wilson, Christie and Rimpilainen, 2008): the virtual environment has the potential to offset some of the issues of time, providing remote access to the network without, for example, taking travelling time out from a busy routine.

The benefits of attending off-the-job training, as opposed to accessing virtual resources, were not always related to the pedagogic content of the training session. The evaluation of the TLRP, which had the most extensive range of training provision, demonstrated that a particularly positive aspect of attending external training courses might relate to the opportunities for networking beyond one's immediate research team. Training courses may provide opportunities to expand beyond the knowledge content of their immediate research project in ways that would be more difficult to achieve through situated learning, but they also provide opportunities for the researcher to 'expand' into a wider research community. This corresponds with Rees et al's observation (2007: 765) that a strength of the TLRP's RCBN provision was the opportunities it provided for researchers to interact "with professional colleagues both within and outside of the workplace". Evans et al (2006: 30 ) similarly stress the value of recognising these kinds of value in off the job training:

".. if conceiving all learning as situated has the effect of confining workers to a particular workplace, on the grounds that (all) learning is highly contextdependent, their opportunity to gain new perspectives, to cross boundaries, and to participate in other communities of practice will be denied."

Opportunities to engage with multiple communities of practice were highly valued by both researchers and project directors across the evaluation of the TLRP. Through their involvement with the TLRP, many researchers felt part of a wider community of educational researchers, for example "the networking and social opportunities 
through TLRP... provide a great support and give huge credibility to the research and to developing as a researcher" (TLRP survey respondent). Despite the fact that, on average, this researcher population had seven years' experience of research prior to beginning work on their TLRP project, they felt that their involvement with the TLRP had provided them with access to a network of researchers whom they would not otherwise have encountered. The value that researchers attached to networking evidences the value of engagement with inter-institutional, inter-project communities as a key element of capacity building.

Participation in academic research can provide a context within which new academics absorb and enact features of university work by working alongside and with others (Trowler and Knight, 2000), thereby developing a shared set of norms, value, and discursive practices. However, in reality, working as a researcher in an academic department often involves only limited opportunities to work alongside others, thereby limiting the opportunities for this kind of learning. Harrison and McKeon's longitudinal study (2008) draws attention to how developing meaningful research can be an isolating experience particularly for second career entrants in teacher education; they highlight how research communities need to respond to new entrants, as well as studying how the researcher accesses that community. Central to positive researcher experiences of professional development across TLRP, WERN and AERS was the role of key people in providing research staff with the support, encouragement, and motivation to participate in the building of their own research capacity. TLRP researchers felt that projects which provided strong interpersonal support and commitment to the individual's professional development were particularly effective at building research capacity. For example, one researcher observed:

"A very supportive and collaborative $P$ l and other research colleagues made this project one of the best experiences of my research career to date. I felt valued throughout the project and the cooperative and collaborative approach of the research team was invaluable both emotionally and professionally. This was a very democratic project which was the most collaborative of my research career." (TLRP researcher)

Feedback from the WERN group reports also indicated that opportunities for working with more experienced colleagues and a mentor were valued and, in particular, the groups where a supportive and non-threatening environment was promoted that nevertheless provided a space for intellectual stimulation and challenge.

Researchers can be isolated, both geographically and institutionally, and there is value in providing research staff with the opportunities to find partners, to share their skills (whether in research or practice) and to learn from the expertise of others. This kind of interpersonal support can act as a catalyst (Fowler and Procter, 2008), in that it enables individual researchers to engage with available professional development activities more effectively. The Meeting of Minds Fellowships sought to establish 
these kinds of relationships through providing funding opportunities for researchers and experts to work together. The overwhelmingly positive response that research staff gave to this limited number of fellowships has led to it continuation and extension within the remit of the British Educational Research Association (BERA).

The expansive research workplace provides opportunities to expand beyond one's host institution, and this is particularly important at a time when there has been a polarisation of the field between research-intensive and other institutions.

Interpersonal support can help provide a vision of coherent career progression, therefore reducing the fragmenting effects of fixed term contracts. Engagement with multiple communities of practice provides fertile ground for future collaborations.

\section{$\underline{\text { Institutional Support and Collaboration }}$}

The social factors described above are central to the development of expansive research workplaces. The workplace is also framed by institutional structures and the evaluations drawn upon in this paper demonstrate the diversity of researcher experience across different institutions, and sometimes across different departments within the same institution, even where funding had been provided from the same source. While people are central to capacity building initiatives, their possible actions are supported or confined by their departments and institutions. For example, a major obstacle for the WERN bursary groups was the lack of time: the time-scales for funding provided for the pilot were short and while one aim of the funding provided to bursary groups was to buy out time for research activity, this does not always seem to have happened; the reason most often cited was the lack of readily available and appropriate supply cover. Possibilities for supply cover related directly to the institution rather than to the bursary groups or to the network as a whole. Gardner (2008: 21) summarises this perspective:

"There was a clear dilemma for the HEI representatives interviewed, namely: how long could the institution continue to facilitate and subsidise the WERN activities before they had to call a halt? Foremost in their minds was the prospect of ultimately drawing in research income but in the teaching intensive institutions, i.e. the large majority, the squeeze on teaching time was becoming more uncomfortable and less manageable for both the institution and the staff involved."

AERS participants also referred to the recurring issue of finding the 'time to do the AERS research'. Generally, academic Fellows fared less favourably than those from other communities, whose employers recognised and formally endorsed the time needed for the work of being a Fellow. It was typical for the Fellows from higher education institutions (HEls) that the original agreements had not been honoured and that most of the AERS work had to be completed in the Fellow's own 'elastic' time. 
The evaluation of the TLRP showed that there were significant discrepancies in provision made to researchers for their own professional development across HEls. Different institutional and departmental cultures contribute to the diversity of opportunities experienced by research staff. At most, some research staff were allocated up to a day a week to develop their own expertise, to write materials for publication, and to, effectively, build their future research capacity. This was undertaken by some through mentoring relationships with more senior colleagues and the opportunity to engage with a wide range of working practices, including research management, within the research project; for others it consisted of access to external training provision. In contrast, other researchers reported that their research projects actively prevented research staff from engaging in professional development activities which did not have immediate relevance to the research project. The revised Concordat (RCUK, 2008) recognises the need for research projects to receive greater guidance on the professional and career management of research staff. We would argue that these strategies need to be made more explicit within research teams and should have a greater degree of standardisation across institutions.

Institutions also differ in the extents to which they support collaboration with other institutions, and external factors including changes in the funding and assessment system for HE have resulted in increasing transient forms of research collaboration (Oancea, 2009). As discussed earlier in this paper, a key aspect of professional development for research staff is access to and engagement with wider communities of practice. However, collaboration is not a shared goal for all HEls. The RAE exercise has fed into a polarisation between research-intensive institutions and other institutions (Pollard, 2008), and institutions frequently compete against one another in the pursuit of research funding. This has had the greatest impact on Wales, although the effects of this centrifugalisation are experienced across the UK. A major focus of WERN has been to counter some of the negative consequences of this through promoting inter-institutional collaboration as a key part of building research capacity. This kind of collaboration was valued within the WERN evaluation:

"The project opened up the opportunity to work with colleagues from other institutions and learn from their experience and expertise. One notable feature was the building of sufficient trust and respect between members, that there was a willingness to share skills and expertise unreservedly between partners from different institutions. I would say that the building of trust and research cooperation between institutions was a key success of the WERN project." [Bursary Group Leader]

Institutional representatives from contexts where educational research is the norm spoke of the way the WERN pilot had contributed to a "shift in attitude" or "consciousness raising " on the part of colleagues who were now, "much more mindful of the work situations and constraints of those working in non $Q R$ funded 
places and more aware of the luxury of being able to carry out research." Working in a group bursary team in the mentor role or as an experienced researcher may have afforded hitherto unavailable insights into working conditions in HEls across Wales. Joining in and engaging in collaborative research work with academics of widely different, little or no research experience, it was felt may have contributed to,

"the development of a crucial empathy on the part of those of us working in research intensive settings. [...] Those executive members who also rolled their sleeves up and got involved in bursaries became aware that something very special was happening and that WERN was out there and something to be reckoned with!"

This links back to the predominant interrelated issues of funding and time, and their importance in enabling research capacity development to take place. Funding alone is not in itself sufficient to guarantee time, there must also be in place an infrastructure that can support research activity. One of the clearest messages to emerge from interviews with WERN executive members who represented their institution, was not about the beneficial gains and modest outcomes achieved to date, but rather the need for the Wales Assembly Government to invest in the development of inter-institutional capacity and put a stronger steer for all Welsh HEls to engage in this collaboration. The challenge is to maintain momentum, and stimulate continued inter-institutional research collaboration, whilst creating opportunities to foster sustainability.

\section{The expansive field of research}

Generally, social practices approaches struggle to account for how communities might change due to participation by new research staff: "much more attention is given to how these processes maintain communities in existence than to how communities themselves change" (Tusting, 2005: 44). While the TLRP community primarily consisted of researchers from HEls, less than two thirds of participants in AERS were from the targeted academic community, with practitioner and policy communities constituting the remainder. While, the large majority of AERS participants reported that they had not joined other networks outside of AERS, perhaps unsurprisingly given participants' limited time, these Networks represent diverse communities in themselves. Participants discussed the benefits of engaging with this community not only in relation to the development of their own research capacity, but also in relation to benefits to their workplace. One of the focus group members explained,

I feel as though it's not only improved my personal capacity for research, I feel as though the local authority, as a whole, has benefited from me participating in this research too. I feel as though the young people that we've been working with, they've benefited out 
of it, you know, the volunteers we've worked with. I think the spinoffs from just one person doing one particular research, one piece of work, has been...you know, the ripples from it, I would say, have been quite far reaching. (Practitioner Fellow)

The nature of these communities has contributed to AERS strengthening Scottish educational research and engendering the co-production of knowledge across traditional boundaries which has the potential for enhancing the integration of research, policy and practice communities. There is evidence that the AERS participants are now looking to the future: two special interest groups have been formed in the Scottish Educational Research Association with the lead being taken by AERS participants. Engagement with multiple communities of practice was valued by both research staff and project directors across these evaluations and there is evidence from each of the Programmes that alliances have been built which have the potential for future collaboration and funding. The sustainability of these networks is an area worthy of future research and, we would argue, future investment.

While the serendipitous rippling outwards of benefits has been identified within the evaluations of these capacity building initiatives, it would be beneficial for Education if explicit attention could be given to how research capacity can effectively by built across the field. Strategic attention is beginning to be focused upon this area: for example the Strategic Forum for Research in Education (SFRE) has identified capacity building as key area to address. Linked to this is the recognition that research capacity needs to be built for different purposes: to sustain the levels of expertise resident in the field in the light of attrition and retirement of existing research staff; to provide opportunities for the development of the field to address perceived methodological, theoretical, and empirical weaknesses; and to create fertile ground for future innovative research.

\section{Conclusion}

This paper has reviewed data from three evaluations of recent capacity building initiatives to analyse how research capacity has been developed within the field of Education. The need to build research capacity within UK social science is widely recognised and demographic data (Mills et al., 2006) suggest that the need to more effectively share expertise is becoming an increasing priority.

The main message from experience in Education over the past decade is that expansive research projects offer the most effective opportunities for building research capacity. While neither a social practices nor a skills-building approach to professional development are sufficient alone, there are different, and often complementary, benefits attached to each: the access, immediacy and contextualised value of the social practices of being engaged with a research project benefit the development of the individual's research capacity and, when organised 
collaboratively, can enable new networking opportunities. External courses provide affordances for the longer term benefits of professional networking and boundary crossing. On-line learning resources and Virtual Research Environments can address concerns over limited time and the need for flexibility, and can provide an additional valued dimension to the building of individuals' research capacity. Recognition of the value of these flexible, accessible professional resources has informed the development of Virtual Research Environments and on-line learning resources by BERA. In planning capacity building and researcher development initiatives, it is imperative to understand the occupational socialisation/learning of researchers, their journeys from novice to expert, the infrastructures and support required, and the opportunities to develop coherent learning trajectories.

The value of engagement with inter-institutional, inter-project communities is repeated throughout the three evaluations in Education. Researchers built their research capacity through expanding beyond the communities and contexts of their immediate research projects. Guidance from key individuals and interpersonal support catalysed these processes and enabled capacity to be developed more effectively. The provision of learning opportunities did not stand-alone: each evaluation recognised the importance of providing interpersonal support to catalyse and guide the individual's engagement with professional development opportunities. These evaluations demonstrate that research capacity building strategies need to promote high motivation to engage in research by providing an opportunity to develop expertise in a supportive and stimulating co-learning environment.

The benefits of networking and collaboration can expand beyond the individual and ripple outwards into the wider research community (and, in some instances, into the practice and policy communities). This was an unplanned aspect of these initiatives, but might usefully be strategised for in future initiatives. There is a pronounced need to encourage collaboration across research teams and institutions: this is necessary to counter the polarising consequences of the RAE and to mitigate against the geographical and institutional isolation experienced by some research staff. Researchers need opportunities to develop expertise by working alongside more knowledgeable peers located in different institutions if research capacity is to be built across the field.

There also appears to be a strong need for institutional and departmental structures to explicitly support capacity building, particularly through the provision of time for capacity building activities and visibility being given to these kinds of activities. We were surprised at the diversity of provision and support provided to early and second career researchers by their more senior colleagues and through their institutions. The diversity of opportunity across HEls is a cause for concern, potentially the new Research Concordat's attention to research management might create a greater equality of opportunity in this area. Institutional support is vital to these processes, particularly in providing time for researchers to develop their professional capacity. If time is not available, then opportunities to learn are restricted and collaboration is 
discouraged. Without collaboration, the building of research capacity is severely impeded.

In summary, the evaluations of the TLRP, WERN, and AERS in Education contribute to the generation of knowledge about effective modes and strategies for researcher development and for building research capacity more generally.

\section{References}

Collinson (2000) 'Social Science Contract Researchers in Higher Education: Perceptions of Craft Knowledge', Work, Employment and Society, 14(11), 159-171

Davies, C. and Holloway, P. (1995) 'Troubling Transformations: Gender Regimes and Organisation Culture in the Academy', in Morley, L. and Walsh, V. (eds.) Feminist Academics: Creative Agents for Change. (London, Taylor and Francis)

Davies, S.M.B. and Salisbury, J. (2009 in press) Building educational research capacity through inter-institutional collaboration: An evaluation of the first year of the Welsh Education Research Network, Welsh Journal of Education

Dyson, A. and Desforges, C. (2002) Building Research Capacity: some possible lines of action. (London, NERF)

Eraut, M. and Hirsch, W. (2007) The significance of workplace learning for individuals, groups and organisations (Oxford, SKOPE, Mongraph 6).

Evans, K., Hodkinson, P., Rainbird, H. and Unwin, L. (2006) Improving workplace learning, (London, Routledge)

Fowler, Z. and Procter, R. (2008) Mapping the Ripples: a taster. (London, Teaching and Learning Research Programme)

Freedman, E.,, Patrick, H., Somekh, B., McIntyre, D. and Wikeley (2000) Quality Conditions for Quality Research: Guidance for good practice in the employment of contract researchers in Education. (Southwell, BERA)

Fuller, A., Unwin, L., Felstead, A., Jewson, N. and Kakavelakis, K. (2007) 'Creating and using knowledge: an analysis of the differentiated nature of workplace learning environments', British Educational Research Journal. 33(5), 743-761

Fuller, A. \& Unwin, L. ( 2004) Expansive learning environments. Integrating organisational and personal development, in Fuller, A., Rainbird, $H$. and Munro,A. (Eds.) Workplace learning in context. (London, Routledge)

Gardner. J. (2008LWelsh Education Research Network: an evaluation. (Belfast, Queens University)

Harrison, J.K. and McKeon, F. (2008) 'The formal and situated learning of beginning teacher educators in England: identifying characteristics for successful induction in the transition from workplace in schools to workplace in higher education', European Journal of Teacher Education. 31(2), 151-168 
Hey, V. (2001) 'The construction of academic time: sub/contracting academic labour in research', Journal of Education Policy. 16(1), 67-84

Lave, J. and Wenger, E. (1991) Situated Learning. (Cambridge, Cambridge University Press)

Mclntyre, D. and Mclntyre, A. (1999) Capacity for research into teaching and learning: Final report to the ESRC Teaching and Learning Programme. (Cambridge)

Mills, D. (2009) 'Scientising the Social Sciences? Demographics and the research economy' in Research Intelligence. p. 13, Issue 108.

Mills, D., Jepson, A., Coxon, T., Easterby-Smith, M., Hawkins, P., and Spencer, J. (2006) Demographic Review of the UK Social Sciences. (Swindon, ESRC)

Munn, P. (2008) 'Building research capacity collaboratively: can we take ownership of our future?' in British Educational Research Journal. 34(4), 413-431

Oancea, A. (2009) 'Fixed-term Employment in Research: questions and experiences' in Research Intelligence p.11, Issue 108.

Pollard, A. (2008) 'Towards New Strategic Initiatives for Research Capacity in Education: a Discussion paper' in Building Research Capacity. 13, 1-6

Pollard, A. (2006) 'Challenges facing educational research. Educational Review Guest Lecture 2005' in Educational Review. 58(3), 251-267

RCUK (2008) The Concordat to Support the Career Development of Researchers. Available online at: http://www.researchconcordat.ac.uk (accessed 7 August 2008)

Reay, D. (2000) '"Dim Dross" Marginalised women both inside and outside the academy' in Women's Studies International Forum, 23(1),13-21

Rees, G., Baron, S., Boyask, R., and Taylor, C. (2007) 'Research capacity building, professional learning and the social practices of educational research' in British Educational Research Journal, 33(5), 761-779

Rees, G. and Power, S. (2007) 'Educational research and the restructuring of the state: the impacts of parliamentary devolution in Wales' in European Educational Research Journal. 6(1), 87-99

Rickinson, M., Walker, M., Rudd, P. (2005) Mid-Term Review of ESRC's Teaching and Learning Research Programme. (NFER)

Taylor, C., Connelly, M., Power, S. and Rees, G. (2007) Formative evaluation of the Applied Educational Research Scheme (AERS). (Scottish Government Social Research).

Taylor, C. (2002) The RCBN Consultation Exercise: Stakeholder Report. (Cardiff: ESRC TLRP RCBN)

The Scottish Government (2003) National Priorities in Education: Performance Report 2003. Downloadable from 
http://www.scotland.gov.uk/Publications/2003/12/18654/30569 (last accessed 21 May 2009).

Trowler, and Knight, P. (2000) 'Coming to know in Higher Education: theorising faculty entry to new work contracts' in Higher Education Research and Development. 19(1), 27-42

Tusting, K. (2006) 'Language and power in communities of practice' in Barton, D. and Tusting, K. (eds) Beyond Communities of Practice. Language, Power and Social Context. (Cambridge, Cambridge University Press)

Wenger, E. (1998) Communities of Practice: Learning, Meaning and Identity. (Cambridge, Cambridge University Press).

Wilson, A., Christie, D. and Rimpilainen, S. (2008) Glow or Glimmer: The Potential of Virtual Environments in Scottish Education. (Edinburgh, AERS Research Commentary No. 2, University of Edinburgh) 